\title{
Smartphone OS and User Emotion and Ethics
}

\author{
Mladen PEČUJLIJA, Duško PETROVIĆ
}

\begin{abstract}
In the light of Gosling theory, we want to answer the question of whether the moral and emotional characteristics (as their Identity Claims and Emotional Regulation) of different smartphones platforms users differ. For this purpose we conducted two researches on a sample of 1500 Serbian students. The obtained results point to the fact that there are statistically significant differences in morality of users of different OS (other socio demographic variables have no significant influence on our dependent variables). Moral characteristics were operationally defined with the Moral Foundations Theory by Haidt. In the second research 809 subjects completed the PANAS X questionnaire. Significant discrete emotions and mood differences were found among different smartphone OS users.
\end{abstract}

Keywords: emotions; mociology; moods; Moral Foundations; OS; smartphone

\section{INTRODUCTION}

"Mociology" or "Mobilology" as it is often referred to is defined as the study of human behaviour in a mobile world and the study of mobile device/phone lifestyles. The word is probably a combination of "mobile" and "sociology". This is the direct by-product of how mobile phones and mobility in modern life lifestyles are affecting and changing human interaction, behaviour, and consumption in the 21st century. Mociology is the fastemerging discipline that studies the impact and effect that mobile phones, mobile technology, and mobile lifestyles are having upon every layer of modern urban societies, cities, and human endeavour. Driving the adoption of new forms of Mociology are the 6 billion mobile phone users worldwide, and the exponential increase in the ways in which mobile phone users demand interactivity from their hand held devices. With mobile phone usage exploding in China, Russia, Brazil, India, Africa and Latin America, and with mobile phone penetration approaching $80 \%$ or more in developed European countries, Mociology and the study of the different impact points in modern life has hastened the need for a deep body of knowledge in this fastemerging field.

A smartphone is a superb mobile phone that includes opportunities for personal digital assistant and a mobile phone. Today's models also typically serve as portable media players and cameras with the touch screen with high resolution, as well as internet browsers that can access and properly display standard web pages rather than those adjusted for mobile devices, and GPS navigation, Wi-Fi and mobile broadband access. The term smartphone, though with its incomplete term meaning and translation, describes the phones with more advanced computing capability than we have with today's conventional (cheaper) phones, although the distinction can be vague and there is not official definition of what constitutes the difference between them. Definitions can also change over time because many ordinary phones now have capabilities that smartphones had in the past. In computing, an operating system (OS) is a set of software responsible for the control and management of devices and computer components as well as performing basic system operations. The operating system incorporates the whole disparate parts of a computer and hides the details of functioning of these parts from the end user. The operating system creates the user workspace handling processes and files, instead of bits, bytes and blocks. Most operating systems come with an application that provides a user interface for handling the operating system such as the interpreter command line and graphical user interface. In addition, the operating system enables other user programs such as editors, translators and web browsers. Operating systems that are commonly present in these devices are Windows Mobile, IOS, Android and Blackberry OS. In our paper we present the three most widely used smartphone operating systems in Serbia: Android, IOS and Black Berry. Although the mobile telephone market has several dominant operating systems the biggest battle is between the two most dominant. Those are, as you have already guessed Android and iOS. UK wireless provider Talk TalkMobile, surveyed 2000 customers (2013) of three major smartphone platforms: iOS, Android, and BlackBerry and uncovered an eclectic mélange of personality traits, some less than flattering, for each user group, the Daily Mail reported. The survey found that iPhone users are vain, ambitious, flirty, and enjoy spending money. The BlackBerry crowd is social, punctual, loud, and ambitious. Meanwhile, Android users are creative, polite, introverted, and tend to drink the most. Dan Meader, Director of Mobile at Talk Talk claims that: "Once you see yourself as a certain type of phone user, it can become a huge part of the way you live your life and people tend to subscribe to the one they feel suits them best. Of course, simply buying a certain type of phone doesn't mean your personality or way of living immediately changes, but the results could suggest that certain types of personality are drawn to different features and functions of certain handsets".

\subsection{Smartphone and Personality}

Smartphones were detected as social interactions mediators but researches also showed that the way of smartphone usage could indicate an individual's personality [1]. According to [2] prior research has shown that personality is linked to user interface preferences, like the surface colour of an application. Some of Big Five personality dimensions, like extraversion/introversion, have also been found to be predictors of our web sites visual esthetics preferences. Chittaranjan et al. also wrote that the personality of a user might also: "determine the kind of functions the individual is disposed to use on the 
phone, for example, of place recommenders that could match the preferences of people with specific traits" [2]. Previous studies have shown that extroverts are more inclined towards the possession of a smart phone [3], dimension of agreeableness is predictor for use smartphones for playing games [4] and low agreeableness is predictor of using smartphones for frequent messages sending [5]. Devaraj et al. found that dimension of conscientiousness creates our estimation of usefulness of technology and our intention to use technology [6]. Also he wrote that conscientiousness moderates relation between these two variables. Neurotic personalities are found to be more feared from technological advances, they claim that using of technological advances creates their work more stressful, and their attitudes toward technological advances are negative. Job-related technology is accepted from the persons high on Openness, they feel less threatened by change implied in adopting technology than persons low on that dimension [6].

Bergman et al. find that Mac users retrieve their files significantly faster than PC users [7]. According to them this difference seems to arise from the fact that Mac users deploy more sophisticated organizational strategies. They claim that unlike PC users, they keep their files closer to the root directory by using small folders that branch sideways with a higher percentage of subfolders. Massey et al. find that individual differences are prevalent in personal information management (PIM) [8]. According to them conscientiousness predicts file organization, particularly PC users' desktops. They find that neurotic people may also keep more desktop files. Indirectly they suggested that systems might be customized for different personalities and that personal digital artifacts signal personality.

But the most important basis for this paper is research done in [9]. Gosling et al. find clear links evidence between individuals and the physical spaces in which they live or work. According to [9] there are relations between personality and personal physical environments. $\mathrm{He}$ explains these relations between personality and physical environment in terms of three separate mediating mechanisms. Identity Claims are when people intentionally structure personal environments to signal aspects of their personality to others. Emotion Regulation is self-directed organization occurring when people actively design personal environments to influence their mood. And Behavioral Residue is when people unconsciously leave informative traces in their environment following past actions. Behavioural Residue is a side-effect of everyday actions and is not intentionally created to affect self or others, in contrast to Identity Claims and Emotion Regulation.

Morality is important aspect of someone's identity. In paper [10] it is stated that there are several face valid links from personality to moral values (they described findings according Big Five theory). They wrote that neuroticism, characterized by anxiety and threat-sensitivity (according to [11]), has clear associations with both binding (to protect group from threat) and individualizing (to secure individuals from coercion). [10] also claimed that [12] supports the suggestion that our response intensity to threat stimuli predicts our support for policies that protect social norms. When they discuss dimension of agreeableness, described by [13] as our empathy capability and our tendencies toward others, Lewis and Bates wrote that this dimension was basically connected to a preference for reduction of suffering and injustice. These capabilities are in the basis of the process of our individualizing. [14] found that dimension of Openness should be used as predictor of our unconventionality. Dimension of Conscientiousness best describes our tendency to responsible behaviour and our relations to our duties [11]. Christopher et al. find this dimension linked with Protestant work ethic values [15].

Smartphone OS is physical space where individuals work (or live) so we stated that the moral characteristics of users of different OS smartphones differ.

\section{EXPERIMENTAL PART}

\subsection{Research 1}

As a basis for our study of morality we used the Haidt's Moral Foundations theory [16]. He stated that these foundations appear in each individual and that all values of civilization are based upon them. To be precise Haidt wrote that the harm foundation is related to our long evolution as mammals with attachment systems and an ability to feel (and dislike) the pain of others. It underlies virtues of kindness, gentleness, and nurturance. Haidt claims that the fairness foundation is related to the evolutionary process of reciprocal altruism and generates ideas of justice, rights, and autonomy. The ingroup foundation as Haidt and collaborates wrote is related to our long history as tribal creatures able to form shifting coalitions and underlies virtues of patriotism and self-sacrifice for the group. The authority foundation was shaped by our long primate history of hierarchical social interactions and represents base for virtues of leadership and followership, including deference to legitimate authority and respect for traditions. The purity foundation was based on our feeling of disgust and represents solid base for our religious behavior.

\subsubsection{Method}

The research contained two phases allowing us to minimize potential problems associated with common source/method bias [17]. In the first part of our research we created a sample of 1500 Serbian students, so we sent to 1500 e-mail addresses: What operating system do you use? (response rate was 74\%). Respondents who use smartphones with Android, IOS and BlackBerry operating system entered the second round of the survey (1014) when they were asked to fill MFQ (response rate was 98\%). In the survey our primary goal was to determine their Moral Foundations. The final sample included 250 randomly selected respondents from each of the operating systems. The survey was completely anonymous.

\subsubsection{Measures}

The Moral Foundations Questionnaire (MFQ) was developed by [16]. MFQ consists of 30 items. According to authors each of these items is a self-report measure of the extent to which an individual endorses each of the five types of moral concerns. They stated that MFQ consists of two parts: in the first part participants rate how relevant 
each of 15 items is to them when making moral judgments; in the second part, participants rate their agreement with items that embody or negate each foundation. Six items per foundation (three from each section) were averaged to produce a score for each person on each foundation. Cronbach's reliability statistics were as follows: Harm $\alpha=$ .77 , Fairness $\alpha=.73$, in group $\alpha=.70$, Authority $\alpha=.79$, and Purity $\alpha=.88$.

\subsubsection{Results}

First of all, by using ANOVA we did not find any gender, age, provider and social status effect or any interactions on moral foundations differences among our subjects (to allow replication of research). From the results we can see that there is a clear impact of the operating system on the expression of moral foundations: harm $(F=$ 5.786, $\left.p=0.003, \eta^{2}=0.04\right)$, fairness $(F=10.885, p=0.000$, $\left.\eta^{2}=0.06\right)$, in group $\left(F=3.866, p=0.022, \eta^{2}=0.02\right)$, authority $\left(F=4.984, p=0.007, \eta^{2}=0.03\right)$ and purity $(F=$ 10.558, $p=0.000, \eta^{2}=0.05$ ) (see Tab. 1). According to Cohen (1992) we can say that all our effect sizes are about to be medium.

Table 1 ANOVA Moral Foundations by OS

\begin{tabular}{|c|c|c|c|c|}
\hline \multicolumn{2}{|c|}{} & $\begin{array}{c}\text { Sum of } \\
\text { Squares }\end{array}$ & $F$ & \multirow{2}{*}{ Sig. } \\
\hline \multirow{3}{*}{ HARM } & Between Groups & 241.517 & 5.786 & .003 \\
\cline { 2 - 5 } & Within Groups & 9955.950 & & \\
\cline { 2 - 5 } & Total & 10197.467 & & \\
\hline \multirow{3}{*}{ FAIRNESS } & Between Groups & 361.950 & 10.885 & .000 \\
\cline { 2 - 5 } & Within Groups & 7930.850 & & \\
\cline { 2 - 5 } & Total & 8292.800 & & \\
\hline \multirow{3}{*}{ AUTHORITY } & Between Groups & 197.600 & 3.866 & .022 \\
\cline { 2 - 5 } & Within Groups & 12191.600 & & \\
\cline { 2 - 5 } & Total & 12389.200 & & \\
\cline { 2 - 5 } & Between Groups & 250.400 & 4.984 & .007 \\
\cline { 2 - 5 } & Within Groups & 11982.725 & & \\
\hline \multirow{3}{*}{ PURITY } & Total & 12233.125 & & \\
\cline { 2 - 5 } & Witheen Groups & 457.817 & 10.558 & .000 \\
\cline { 2 - 5 } & Total Groups & 10342.050 & & \\
\hline
\end{tabular}

Post hoc analysis (see Tab. 2) has shown the following: Dimension Harm was significantly more pronounced in users of Android OS than BlackBerry OS and IOS users. The difference on this dimension between the Android OS and IOS users is not significant. Dimension Fairness is significantly more pronounced in users of Android OS than BlackBerry, and also in users of IOS compared to BlackBerry users. There is not a significant difference in the measurements between the Android and IOS users. Ingroup dimension is significantly more pronounced among Android users than BlackBerry users. Between IOS and BlackBerry users the difference is not significant and it is the same between Android and IOS users. Dimension Authority is significantly more pronounced among Android users than BlackBerry users, while on this dimension there is not a significant difference between Android and IOS users nor between IOS and BlackBerry users. Android OS users have more pronounced Purity dimension than the users of BlackBerry OS as well as IOS users. The difference between Android and IOS users is not significant in this regard.

The obtained results show that users of different OS have different Moral Foundations, and that this difference is at the level of statistical significance for each of them. On the other hand, the post hoc analysis has pointed to one fact - first of all, there is no significant difference in terms of morality between Android and IOS users, and they can be almost equally classified (same Identity, according to Gosling), and that the real difference is evident in BlackBerry population on all dimensions. Given that this OS is mainly associated with all forms of management activities, the results tell us it is mostly effective about the magnitude of morality in this population.

Table 2 ANOVA Moral Foundations by OS post hoc (Tukey HHSD)

\begin{tabular}{|c|c|c|c|c|}
\hline $\begin{array}{l}\text { Dependent } \\
\text { Variable }\end{array}$ & $\begin{array}{l}\text { (I) OS in } \\
\text { use }\end{array}$ & $\begin{array}{c}(J) \text { OS in } \\
\text { use }\end{array}$ & $\begin{array}{c}\text { Mean } \\
\text { Difference } \\
(I-J)\end{array}$ & Sig. \\
\hline \multirow{6}{*}{ HARM } & \multirow{2}{*}{ Android } & IOS & .438 & .668 \\
\hline & & BlackBerry & $1.675^{*}$ & .003 \\
\hline & \multirow{2}{*}{ IOS } & Android & -.438 & .668 \\
\hline & & BlackBerry & $1.237^{*}$ & .042 \\
\hline & \multirow{2}{*}{ BlackBerry } & Android & $-1.675^{*}$ & .003 \\
\hline & & IOS & $-1.237^{*}$ & .042 \\
\hline \multirow{6}{*}{ FAIRNESS } & \multirow{2}{*}{ Android } & IOS & -.150 & .942 \\
\hline & & BlackBerry & $1.762^{*}$ & .000 \\
\hline & \multirow{2}{*}{ IOS } & Android & .150 & .942 \\
\hline & & BlackBerry & $1.912^{*}$ & .000 \\
\hline & \multirow{2}{*}{ BlackBerry } & Android & $-1.762^{*}$ & .000 \\
\hline & & IOS & $-1.912^{*}$ & .000 \\
\hline \multirow{6}{*}{ INGROUP } & \multirow{2}{*}{ Android } & IOS & 1.000 & .181 \\
\hline & & BlackBerry & $1.550^{*}$ & .017 \\
\hline & \multirow{2}{*}{ IOS } & Android & -1.000 & .181 \\
\hline & & BlackBerry & .550 & .594 \\
\hline & \multirow{2}{*}{ BlackBerry } & Android & $-1.550^{*}$ & .017 \\
\hline & & IOS & -.550 & .594 \\
\hline \multirow{6}{*}{ AUTHORITY } & \multirow{2}{*}{ Android } & IOS & .650 & .478 \\
\hline & & BlackBerry & $1.750^{*}$ & .005 \\
\hline & \multirow{2}{*}{ IOS } & Android & -.650 & .478 \\
\hline & & BlackBerry & 1.100 & .123 \\
\hline & \multirow{2}{*}{ BlackBerry } & Android & $-1.750^{*}$ & .005 \\
\hline & & IOS & -1.100 & .123 \\
\hline \multirow{6}{*}{ PURITY } & \multirow{2}{*}{ Android } & IOS & .788 & .286 \\
\hline & & BlackBerry & $2.350^{*}$ & .000 \\
\hline & \multirow{2}{*}{ IOS } & Android & -.788 & .286 \\
\hline & & BlackBerry & $1.563^{*}$ & .008 \\
\hline & \multirow{2}{*}{ BlackBerry } & Android & $-2.350^{*}$ & .000 \\
\hline & & IOS & $-1.563^{*}$ & .008 \\
\hline
\end{tabular}

On the other hand, it is evident that the Moral Foundations affect the preference of OS so that we can say that the managers users of Android OS have most pronounced dimensions of Purity and Ingroup, so they most tend to purity in all kinds of relationships and are very loyal to the groups to which they belong (e.g. their firms). In the terms of virtues, we can say that Android users are striving to live in an elevated, noble way more than other users. Also their virtues of patriotism and self-sacrifice for the group are higher than the other users (they are loyal to Android). On the other hand, the users of IOS most notable dimensions are Fairness and Harm, hence they are concerned about fairness and empathy for other people. So, IOS users are more kind and gentle than the other users. Ideas of justice, rights, and autonomy are also characteristic for them. The most pronounced dimensions in beneficiaries of BlackBerry OS are Ingroup and Fairness; therefore, they are loyal to the group to which they belong, and they also advocate fair treatment. So they are also interested in justice, rights autonomy, patriotism and self-sacrifice. 


\subsection{Research 2}

Second important mediator of relations between personality and physical environment is Emotional Regulation [9]. In our case physical environment is smartphone OS.

Martin wrote that an appreciable amount of consumer research has investigated how moods influence consumers [18]. A mood is an emotional state. Moods differ from emotions in that they are less specific, less intense, and less likely to be triggered by a particular stimulus or event. Moods generally have either a positive or negative valence. In other words, people typically speak of being in a good mood or a bad mood. According to him studies have explored how moods impact on recall [19], shopping intentions [20], the amount of cognitive elaboration engaged in by consumers [21], and evaluations of brand extensions, advertisements [22], and music [23]. Some of researchers find out that emotions play important role in smartphone using [3, 24]. Also it is found that neurotic personalities are likely to view technological advances in their work as threatening and stressful, and to have generally negative thought processes when considering technological advances [6]. Ehrenberg found that neurotic individuals spent more time text messaging and reported stronger mobile phone addictive tendencies [5].

In this study we want to see whether or not there are significant discrete emotional and mood differences between different smartphones users. We operationally defined mood and emotions according to Watson theory by using PANAS X (Positive and Negative Affect Schedule Expanded Form) questionnaire. In this research we used this dimensional model to identify the primary orthogonal dimensions of emotions as Positive Affect and Negative Affect $[25,26]$. Using this model, high Positive Affect is characterized as "active, excited" while low Positive Affect is "drowsy, dull". High Negative Affect is "distressed, fearful" while low Negative Affect is "calm, relaxed". In this model, the higher level reflects the valence of the mood descriptors (i.e., whether they represent negative or positive states), whereas the lower level reflects their specific content (the distinctive qualities of the individual affects).

\subsubsection{Method}

The research contained two phases allowing us to minimize potential problems associated with common source/method bias [17]. Students using known operating system were asked to complete a PANAS X questionnaire. The response rate was very high (79\%). Afterwards we carried out the random sample equalization of examinees according to the OS they used (Android, IOS, and BlackBerry) so that the final processing included 809 examinees (267 Android users, 286 IOS users, and 256 Blackberry users). As in the first research ANOVA showed that there was not any gender, age, provider and social status effect or any interactions on the dependent variables (PANAS X scales) neither between groups nor within groups.

\subsubsection{Measurements}

The examinees filled in the PANAS X questionnaire (Positive and Negative Affect Schedule - Expanded Form). The PANAS-X [27] consists of 60 words and phrases that are ranked on a Likert-type scale from 1 to 5 . This questionnaire not only measures the two original higher order scales (GPE - General Positive Emotion and GNE General Negative Emotion), but also 11 specific emotions: Fear, Sadness, Guilt, Hostility, Shyness, Fatigue, Surprise, Joviality, Self-Assurance, Attentiveness, and Serenity. Cronbach's alpha coefficients for GPE are 0.83 and for GNE are 0.89, however the Cronbach's alpha coefficients for specific emotions are as follows: Fear $\alpha=.87$, Sadness $\alpha=.87$, Guilt $\alpha=.88$, Hostility $\alpha=.85$, Shyness $\alpha=.83$ Fatigue $\alpha=.88$, Self-Assurance $\alpha=.83$.

Table 3 PANAS $X$ correlation matrix for all variables

\begin{tabular}{|c|c|c|c|c|c|c|c|c|c|c|c|c|c|c|}
\hline & Mean & 1 & 2 & 3 & 4 & 5 & 6 & 7 & 8 & 9 & 10 & 11 & 12 & 13 \\
\hline Fear & 12.87 & 1 & & & & & & & & & & & & \\
\hline Hostility & 13.46 & .54 & 1 & & & & & & & & & & & \\
\hline Guilt & 11.72 & .65 & .566 & 1 & & & & & & & & & & \\
\hline Sadness & 9.34 & .61 & .520 & .619 & 1 & & & & & & & & & \\
\hline Joviality & 26.51 & -.14 & .077 & -.189 & -.227 & 1 & & & & & & & & \\
\hline Self Assur & 19.45 & -.17 & .054 & -.209 & -.163 & .513 & 1 & & & & & & & \\
\hline Attentiveness & 13.77 & -.21 & -.071 & -.297 & -.207 & .601 & .598 & 1 & & & & & & \\
\hline Shyness & 9.16 & .57 & .353 & .479 & .443 & -.049 & -.191 & -.144 & 1 & & & & & \\
\hline Fatigue & 9.86 & .43 & .370 & .377 & .457 & -.084 & -.015 & -.113 & .346 & 1 & & & & \\
\hline Serenity & 10.62 & -.32 & -.148 & -.265 & -.227 & .505 & .410 & .471 & -.173 & -.052 & 1 & & & \\
\hline Surprise & 6.71 & .40 & .418 & .371 & .366 & .136 & -.005 & -.020 & .296 & .276 & -.024 & 1 & & \\
\hline GPE & 33.79 & -.18 & .036 & -.250 & -.209 & .771 & .662 & .799 & -.097 & -.089 & .472 & .070 & 1 & \\
\hline GNE & 20.35 & .88 & .701 & .768 & .652 & -.121 & -.118 & -.222 & .524 & .442 & -.295 & .438 & -.172 & 1 \\
\hline
\end{tabular}

Tab. 3 shows that the correlations among the variables are between 0.14 to 0.88 . Highly significant correlations are between the GNE and variables which create it. The same is with the GPE. Generally speaking, GPE and GNE are moderately pronounced in our examinees, and the same applies to other emotions.

\subsubsection{Results}

ANOVA shows that there is a difference between examinees regarding what OS they use in GNE $(F=4.052$, $\left.p=0.018, \eta^{2}=0.052\right)$, fear $\left(F=3.149, p=0.043, \eta^{2}=\right.$ $0.041)$, hostility $\left(F=3.597, p=0.028, \eta^{2}=0.049\right)$ and guilt $\left(F=5.536, p=0.004, \eta^{2}=0.061\right)$. According to Cohen (1988) we can say that all our effect sizes are about to be medium. 
Post hoc analysis (Tab. 4) shows that in terms of GNE there is no statistically significant difference between Android OS and BlackBerry OS users and the GNE is more pronounced in BlackBerry users. A difference exists between BlackBerry OS and iOS users profile but is not statistically significant. Generally speaking, GNE is the most pronounced in BlackBerry OS users and the least pronounced in Android users.

When we talk about the discrete emotion Fear the situation is identical. Fear is the highest in Black Berry users and the lowest in the Android customers. The difference in intensity of fear between BlackBerry OS and
Android OS users is statistically significant. Hostility is also highly pronounced in BlackBerry OS users and minimally in Android OS users. The difference between the Android OS and BlackBerry OS users is statistically significant, while the difference between iOS and BlackBerry OS user is not at the level of statistical significance. Guilt is least prevalent in the Android OS users, while in BlackBerry OS and IOS users it is almost equally prominent. There is a statistically significant difference in intensity of guilt between the Android OS users on one hand, and iOS and BlackBerry users on the other.

Table 4 PANAS $X$ by OS Post Hoc analysis (Tukey HHSD)

\begin{tabular}{|c|c|c|c|c|c|}
\hline Dependent Variable & (I) OS in use & $(J)$ OS in use & Mean Difference $(I-J)$ & Std. Error & Sig. \\
\hline \multirow{6}{*}{ General Negative Emotion } & \multirow{2}{*}{ Android } & IOS & -.800 & .575 & .346 \\
\hline & & BlackBerry & $-1.683^{*}$ & .591 & .013 \\
\hline & \multirow{2}{*}{ IOS } & Android & .800 & .575 & .346 \\
\hline & & BlackBerry & -.883 & .582 & .283 \\
\hline & \multirow{2}{*}{ BlackBerry } & Android & $1.683^{*}$ & .591 & .013 \\
\hline & & IOS & .883 & .582 & .283 \\
\hline \multirow{6}{*}{ Fear } & \multirow{2}{*}{ Android } & IOS & -.596 & .397 & .291 \\
\hline & & BlackBerry & $-1.018^{*}$ & .408 & .034 \\
\hline & \multirow{2}{*}{ IOS } & Android & .596 & .397 & .291 \\
\hline & & BlackBerry & -.422 & .402 & .545 \\
\hline & \multirow{2}{*}{ BlackBerry } & Android & $1.018^{*}$ & .408 & .034 \\
\hline & & IOS & .422 & .402 & .545 \\
\hline \multirow{6}{*}{ Hostility } & \multirow{2}{*}{ Android } & IOS & -.165 & .306 & .852 \\
\hline & & BlackBerry & $-.799^{*}$ & .314 & .030 \\
\hline & \multirow{2}{*}{ IOS } & Android & .165 & .306 & .852 \\
\hline & & BlackBerry & -.634 & .309 & .101 \\
\hline & \multirow{2}{*}{ BlackBerry } & Android & $.799^{*}$ & .314 & .030 \\
\hline & & IOS & .634 & .309 & .101 \\
\hline \multirow{6}{*}{ Guilt } & \multirow{2}{*}{ Android } & IOS & $-1.092^{*}$ & .377 & .011 \\
\hline & & BlackBerry & $-1.112^{*}$ & .387 & .012 \\
\hline & \multirow{2}{*}{ IOS } & Android & $1.092^{*}$ & .377 & .011 \\
\hline & & BlackBerry & -.020 & .381 & .998 \\
\hline & \multirow{2}{*}{ BlackBerry } & Android & $1.112^{*}$ & .387 & .012 \\
\hline & & IOS & .020 & .381 & .998 \\
\hline
\end{tabular}

\section{DISCUSSION}

The results show that users of Android OS are least prone to aggressive behavior, feeling of guilt and fear and they also have the least pronounced GNE. On the other hand, these emotions are highest in BlackBerry OS users and IOS users show a kind of golden mean. We can say that the negative discrete emotions are primarily the features of BlackBerry users. If we try to explain these results, we can say that BlackBerry OS is linked to people who have either control or tend towards management. On the other side Android OS users present population of the least prone to negative emotional reactions. If we accept the notion that GNE carries a tendency towards more detailed processing of information in the decision-making process, it is expected that the population of BlackBerry OS users has the most pronounced GNE, and that the users of IOS, and even more likely the users of Android, are associated with carelessness and heuristics in processing of information and decision-making. This research has shown that people who are prone to different emotional reaction opt to use various smartphones OS, but it would be highly interesting in a future research to shed light on the reverse relation - whether the use of different smartphone OS affects the mood and emotional reactions of their customers. This research, pioneer in its nature, shows us a simple fact: different smartphone OS-different student's morality, emotions and moods. These results should be useful for consumer behavior research in Serbia and also a direction for future consumer behavior research. Also this research shows that mociology as a new branch has sense. But we have to highlight opposite relationship: how smartphone's OS impact our morality, emotions and moods and that will be a very interesting research question for the future. This research has some limitations: cultural dimension is included (only Serbian students). Age is also limited because research is done on student population. Morality is only discussed according to Haidt's moral foundations theory and emotions and moods are detected by PANAS X. So, according to this research it is good for us to know the user's OS if we want to know something but not everything about their morality, emotions and moods. Also limitation of this research is OS which we include in this research: BlackBerry is today marginal. All in all, we can agree with Ralph Simon (2005) who claims: If you have a mobile phone or a mobile multimedia computer as they are now being called, you are clearly a mociologist.

One serious implication is that smartphone OS might be customized for different personalities. We also advance 
personality theory, showing that smartphone OS choice signals personality.

\section{CONCLUSION}

In the light of Gosling's work we can say that one of the main reasons for Android's popularity is its adaptability. Namely, the users can adapt this OS to their individual habits and needs (Identity Claims and Emotional Regulation). On the other hand, iOS, Apple's original system found on the iPhone, is much less flexible so Identity Claims and Emotional regulation are restricted. To adapt iOS, it is necessary to illegally remove hardware restriction using a system popularly known as Jailbreak (iOS users are higher on guilt than Android users). The general impression is that managing information is also easier with Android.

These results implicate that a possible approach to smartphone OS is to develop multiple-personality smartphones and tablets that provide true isolation between the enterprise and personal domains: a completely different set of screens when you access business apps and when you access personal apps.

\section{REFERENCES}

[1] Butt, S. \& Phillips, J. G. (2008). Personality and selfreported mobile phone use. Computers in Human Behavior, 24(2), 346-360. https://doi.org/10.1016/j.chb.2007.01.019

[2] Chittaranjan, G., Blom, J., \& Gatica-Perez, D. (2013). Mining large-scale smartphone data for personality studies. Personal and Ubiquitous Computing, 17(3), 433-450. https://doi.org/10.1007/s00779-011-0490-1

[3] Lane, W. \& Manner, C. (2012). The Impact of Personality Traits on Smartphone Ownership and Use. International Journal of Business and Social Science, 2(17), 22-28

[4] Phillips, J. G., Butt, S., \& Blaszczynski, A. (2008). Personality and self-reported use of mobile phones for games. Cyber Psychology and Behavior, 9(6), 753-758. https://doi.org/10.1089/cpb.2006.9.753

[5] Ehrenberg, A., Juckes, S., White, K. M., \& Walsh, S. P. (2008). Personality and self-esteem as predictors of young people's technology use. Cyber Psychology and Behavior, 11(6), 739- 741. https://doi.org/10.1089/cpb.2008.0030

[6] Devaraj, S., Easley, R. F., \& Crant, J. M. (2008). How Does Personality Matter? Relating the Five Factor Model to Technology Acceptance and Use. Information Systems Research, 19(1), 93-105. https://doi.org/10.1287/isre.1070.0153

[7] Bergman, O., Whittaker, S., Sanderson, M., Nachmias, R., \& Ramamoorthy, A. (2012). How do we find personal files? the effect of OS, presentation \& depth on file navigation? Proceedings of the 2012 conference on Computer Human Interaction (CHI '12), 2977-2980. https://doi.org/10.1145/2207676.2208707

[8] Massey, C., Ten Brook, S., Tatum, C., \& Whittaker, S. (2014). PIM and personality: What do our personal file systems say about us? Proceedings of the 2014 conference on Computer Human Interaction (CHI'14), 3695-3704. https://doi.org/10.1145/2556288.2557023

[9] Gosling, S. D., Ko, S. J., Mannarelli, T., \& Morris, M. E. (2002). A room with a cue: personality judgments based on offices and bedrooms. Journal of personality and social psychology, 82(3), 379-394. https://doi.org/10.1037//0022-3514.82.3.379

[10] Lewis, G. J. \& Bates, T. C. (2011). From left to right: How the personality system allows basic traits to influence politics via characteristic moral adaptations. British Journal of Psychology, 102(3), 546-558. https://doi.org/10.1111/j.2044-8295.2011.02016.x

[11] Costa, P. T. \& McCrae, R. R. (1992). Revised NEO Personality Inventory (NEO-PIR) and NEO Five-Factor Inventory professional manual. Odessa, FL: Psychological Assessment Resources, Inc.

[12] Oxley, D. R., Smith, K. B., Alford, J. R., Hibbing, M. V., Miller, J. L., Scalora, M., \& Hibbing, J. R. (2008). Political attitudes vary with physiological traits. Science, 321(5896), 1667-1670. https://doi.org/10.1126/science.1157627

[13] Jensen-Campbell, L. A. \& Graziano, W. G. (2001). Agreeableness as a moderator of interpersonal conflict. Journal of Personality, 69(2), 323-362. https://doi.org/10.1111/1467-6494.00148

[14] McCrae, R. R. (1996). Social consequences of experiential openness. Psychological Bulletin, 120(3), 323-337. https://doi.org/10.1037/0033-2909.120.3.323

[15] Christopher, A. N., Zabel, K. L., \& Jones, J. R. (2008). Conscientiousness and work ethic ideology: A facet-level analysis. Journal of Individual Differences, 29(4), 189-198. https://doi.org/10.1027/1614-0001.29.4.189

[16] Haidt, J. (2007). The New Synthesis in Moral Psychology. Science, 316(5827), 998-1002. https://doi.org/10.1126/science.1137651

[17] Podsakoff, P. M., MacKenzie, S. B., Lee, J. Y., \& Podsakoff, N. P. (2003). Common Method Biases in Behavioral Research: A Critical Review of the Literature and Recommended Remedies. Journal of Applied Psychology, 88(5), 879-903. https://doi.org/10.1037/0021-9010.88.5.879

[18] Martin, B. (2003). The Influence of Gender on Mood Effects in Advertising. Psychology \& Marketing, 20(3), 249-273. https://doi.org/10.1002/mar.10070

[19] Lee, A. Y. \& Sternthal, B. (1999). The effects of positive mood on memory. Journal of Consumer Research, 26(2), 115-127. https://doi.org/10.1086/209554

[20] Swinyard, W. R. (1993). The effects of mood, involvement, and quality of store experience on shopping intentions. Journal of Consumer Research, 20(2), 271-280. https://doi.org/10.1086/209348

[21] Batra, R. \& Stayman, D. M. (1990). The role of mood in advertising effectiveness. Journal of Consumer Research, 17(2), 203-214. https://doi.org/10.1086/208550

[22] Goldberg, M. E. \& Gorn, G. J. (1987). Happy and sad TV programs: How they affect reactions to commercials. Journal of Consumer Research, 14(3), 387-403. https://doi.org/10.1086/209122

[23] Holbrook, M. B. \& Gardner, M. P. (2000). Illustrating a dynamic model of the mood-updating process in consumer behavior. Psychology \& Marketing, 17(3), 165-194. https://doi.org/10.1002/(SICI)1520-6793(200003)17:3<165::AIDMAR $1>3.0 . C 0 ; 2-5$

[24] Bianchi, A. \& Phillips, J. (2005). Psychological predictors of problem mobile phone use. Cyber Psychology and Behavior, 8(1), 39-51. https://doi.org/10.1089/cpb.2005.8.39

[25] Tellegen, A. (1985). Structures of mood and personality and their relevance to assessing anxiety, with an emphasis on self-report. In Tuma, A. H. \& Maser, J. D. (Eds.), Anxiety and the anxiety disorders Hillsdale, NJ: Erlbaum, 681-706. https://doi.org/10.4324/9780203728215-49

[26] Watson, D. \& Tellegen, A. (1985). Toward a consensual structure of mood. Psychological Bulletin, 98(2), 219-235. https://doi.org/10.1037/0033-2909.98.2.219

[27] Watson, D. \& Clark, L.A. (1991). Self- versus peer ratings of specific emotional traits: Evidence of convergent and discriminant validity. Journal of Personality and Social Psychology, 60(6), 927-940. https://doi.org/10.1037/0022-3514.60.6.927 


\section{Contact information:}

Mladen PEČUJLIJA, PhD, associate professor

(Corresponding author)

University of Novi Sad, Faculty of Technical Sciences,

Trg Dositeja Obradovića 6,

21000 Novi Sad, Serbia

E-mail: ikmladen@uns.ac.rs

Duško PETROVIĆ, PhD student

University of Novi Sad, Faculty of Technical Sciences,

Trg Dositeja Obradovića 6,

21000 Novi Sad, Serbia

E-mail: dusko.petrovic@gmail.com 